\title{
Article \\ Analysis of Nucleation and Glass Formation by Chip Calorimetry
}

\author{
Meng Gao $\mathbb{(}$, Chengrong Cao and John H. Perepezko * \\ Department of Materials Science and Engineering, University of Wisconsin-Madison, 1509 University Ave., \\ Madison, WI 53706, USA; mgao63@wisc.edu (M.G.); ccao32@wisc.edu (C.C.) \\ * Correspondence: perepezk@engr.wisc.edu; Tel.: +1-608-2631678
}

check for updates

Citation: Gao, M.; Cao, C.; Perepezko, J.H. Analysis of Nucleation and Glass Formation by Chip Calorimetry. Appl. Sci. 2021, 11, 7652. https://doi.org/10.3390/ app11167652

Academic Editors: Johannes Lerchner and Christoph Schick

Received: 30 July 2021

Accepted: 18 August 2021

Published: 20 August 2021

Publisher's Note: MDPI stays neutral with regard to jurisdictional claims in published maps and institutional affiliations.

Copyright: (c) 2021 by the authors. Licensee MDPI, Basel, Switzerland. This article is an open access article distributed under the terms and conditions of the Creative Commons Attribution (CC BY) license (https:// creativecommons.org/licenses/by/ $4.0 /)$.

\begin{abstract}
The advent of chip calorimetry has enabled an unprecedented extension of the capability of differential scanning calorimetry to explore new domains of materials behavior. In this paper, we highlight some of our recent work: the application of heating and cooling rates above $10^{4} \mathrm{~K} / \mathrm{s}$ allows for the clear determination of the glass transition temperature, $T_{g}$, in systems where $T_{g}$ and the onset temperature for crystallization, $T_{x}$, overlap; the evaluation of the delay time for crystal nucleation; the discovery of new polyamorphous materials; and the in-situ formation of glass in liquid crystals. From these application examples, it is evident that chip calorimetry has the potential to reveal new reaction and transformation behavior and to develop a new understanding.
\end{abstract}

Keywords: chip calorimetry; glass transition; nucleation kinetics; delay time; polyamorphism; amorphous materials; liquid crystal

\section{Introduction}

In many materials processing technologies, the thermal history involves various heating and cooling cycles as well as isothermal treatment. With the treatment of bulk components, the rate of heating and cooling is limited and is not constant throughout the volume. While the thermal history can be calculated by a heat flow analysis, the non-uniform thermal history can yield microstructural gradients and varying properties that confound accurate measurements. By a careful design of the thermal protocol and reduced sample volumes, a uniform thermal history can be attained to enable the use of standard calorimetry techniques to measure material properties accurately. However, the standard techniques only allow for a limited heating and cooling rate of less than a few $\mathrm{K} / \mathrm{s}$. The recent advances in chip calorimetry have circumvented this limitation and allow for unprecedented rates of $2-5 \times 10^{4} \mathrm{~K} / \mathrm{s}$, which has vastly expanded the capability of calorimetry to examine thermally activated reactions and phase transformations.

In this paper, the application of chip calorimetry is demonstrated for the examination of glass transition temperature $T_{g}$ and crystallization of metallic glass (MG) and amorphous polymers, and the development of polyamorphism as well as glass formation in liquid crystals. In each case, the unique capability of chip calorimetry has enabled the exploration of new and novel transformation behavior that has permitted the development of a new understanding.

\section{Materials and Methods}

\subsection{Metallic Glass Samples}

The ingots of the compositions of $\mathrm{Al}_{92} \mathrm{Sm}_{8}$ and $\mathrm{La}_{60} \mathrm{Ni}_{15} \mathrm{Al}_{25}$ were prepared by arc melting the elemental components several times in a Ti-gettered argon atmosphere to ensure homogeneity. For the $\mathrm{Mg}_{65} \mathrm{Cu}_{25} \mathrm{Gd}_{10}$ alloy, the ingot was prepared by an induction melting method in an argon atmosphere. Then, the ribbon-like samples were prepared by single-rolling melt spinning on a copper wheel with a tangential speed of $55 \mathrm{~m} / \mathrm{s}$. The thickness and the width of the ribbon-like samples were about $20 \times 2 \mu \mathrm{m} \times \mathrm{mm}$. The 
melt spinning process was performed in inert argon gas. The structure of these as-cast samples and the annealed samples was characterized by X-ray diffraction. Meanwhile, the thermal properties of the above samples were measured by conventional diamond DSC (Perkin Elmer (Downers Grove, IL, USA)). The TEM tests were conducted on a Tecnai T12 instrument at $120 \mathrm{kV}$. The in-situ continuous heating, the annealing treatment, and the following thermal analyses were performed on a high-rate Flash DSC platform (Flash DSC2, Mettler Toledo (Columbus, OH, USA)) with chip sensor (UFS1). TEM samples from the annealed Flash DSC samples were prepared by Zeiss Auriga Focused Ion Beam (FIB) with a $10 \mathrm{nA}$ FIB current and a $2 \mathrm{kV}$ voltage to avoid sample damage.

\subsection{Polybutylene Terephthalate (PBT) Sample}

The commercial PBT film-like specimen was purchased from Sigma-Aldrich Co. (Product number was GF14031447 (St. Louis, MO, USA)). The thickness was $0.55 \mathrm{~mm}$, and the melting temperature was about $250^{\circ} \mathrm{C}$. For PBT, the critical cooling rate for glass formation is about $1000 \mathrm{~K} / \mathrm{s}$ [1]. To prepare the totally amorphous sample, one tiny piece was cut from the film-like commercial specimen and then was placed on the sample area of the chip sensor. The small piece firstly was heated to $270{ }^{\circ} \mathrm{C}$ and then was cooled down with the cooling rate of $10^{4} \mathrm{~K} / \mathrm{s}$. The obtained amorphous sample was subjected to a series of annealing treatments with different annealing times under the same annealing temperature.

\subsection{D-Mannitol Sample}

D-mannitol (Aldrich, $>99 \%$ ) was used as received. If cooled rapidly enough $(>30 \mathrm{~K} / \mathrm{s}$ ), the supercooled liquid (SCL) avoids crystallization, entering the glassy state below the $T_{g}$ of $284 \mathrm{~K}$ (the glass transition temperature $T_{g}$ ) [2,3]. Before measurement, the sample was heated to $15 \mathrm{~K}$ above the melting point $(440 \mathrm{~K})$ for $10 \mathrm{~s}$ to allow for the development of good contact with the detector chip. The schedule for a typical Flash DSC measurement involves melting $(100 \mathrm{~K} / \mathrm{s}$ heating to $455 \mathrm{~K})$, quenching $\left(10^{3} \mathrm{~K} / \mathrm{s}\right.$ cooling to $\left.223 \mathrm{~K}\right)$, annealing at temperatures ranging from $288 \mathrm{~K}$ to $333 \mathrm{~K}$ with annealing times ranging from $0 \mathrm{~s}$ to $10^{4} \mathrm{~s}$, and quenching and reheating $(100 \mathrm{~K} / \mathrm{s})$ to temperature above the melting point [4]. The calibration of each chip was performed by the manufacturer and further validated against the melting point of D-mannitol.

\subsection{Itraconazole (ITZ) Sample}

The sample material—itraconazole (ITZ) — was supplied by Alfa Aesar (Tewksbury, MA, USA) with purity greater than $99 \%$ and used without further purification. The starting material was completely crystalline with a melting point of $440 \mathrm{~K}$. For ITZ, it was recently reported that at slow cooling (generally slower than $10 \mathrm{~K} / \mathrm{min}$ ), the isotropic liquid transforms to a nematic phase and then to a smectic phase, and finally produces a smectic ordered glassy solid [5]. However, at fast cooling (from $0.5 \mathrm{~K} / \mathrm{s}$ to $20 \mathrm{~K} / \mathrm{s}$ ), smectic ordering can be avoided altogether or avoided partially [5]. To further obtain different structural ordered glassy solids in situ, before measurement, the sample was heated to about $33 \mathrm{~K}$ above the melting point for $2 \mathrm{~s}$ to allow for the development of good contact with the detector chip, then the molten sample was quenched at a series of cooling rate from 10 to $10^{4} \mathrm{~K} / \mathrm{s}$. The subsequent reheating curve at $10^{3} \mathrm{~K} / \mathrm{s}$ was used to conduct the thermal analyses.

\section{Results and Discussions}

\subsection{Nucleation and Primary Crystallization}

3.1.1. Separation of Glass Transition Temperature and Crystallization Temperature by Increasing Heating Rate in Marginal Al-Based MG

For most MG systems with good glass formation ability, the glass transition signal is strong enough to be detected in the heating DSC traces, which makes it possible to measure the glass transition temperature and the supercooled liquid region by the conventional DSC method. However, for marginal MGs such as the Al-based MGs, the glass 
transition signal is prone to be overlapped by a primary crystallization for $\mathrm{Al}$ nanocrystals precipitation [6,7]. Thus, the traditional DSC is not a good thermal analysis tool to observe the glass transition of Al-based MGs. On the other hand, considering that the glass transition and crystallization are significantly different kinetic processes, they should follow different evolution paths with different heating rates so that the two kinetic signals are separated under higher heating rates. Here, we take the typical $\mathrm{Al}_{92} \mathrm{Sm}_{8} \mathrm{MG}$ as an example. The conventional DSC with heating rate of $0.33 \mathrm{~K} / \mathrm{s}$ was applied to measure the heat flow curve shown in Figure 1a. It is clear that the conventional DSC heat flow curve only displays the primary and secondary crystallization peaks as shown in Figure 1b, and there is no clearly defined glass transition signal. In contrast, the maximum heating and cooling rates for high-rate Flash DSC instrument with chip sensors (Flash DSC2, Mettler Toledo ((Columbus, $\mathrm{OH}, \mathrm{USA}))$ ) are $4 \times 10^{4}$ and $4 \times 10^{3} \mathrm{~K} / \mathrm{s}$, and the temperature range is between $-90^{\circ} \mathrm{C}$ and $450{ }^{\circ} \mathrm{C}[8,9]$. The optical picture of tiny MG sample being loaded onto the Flash DSC chip is shown in Figure 1b, and the inserted optical picture gives the ribbon-like Al-based MG sample. A series of Flash DSC heat flow curves corresponding to different heating rates from $50 \mathrm{~K} / \mathrm{s}$ to $1000 \mathrm{~K} / \mathrm{s}$ were measured as shown in Figure 1c. For all heating rates by Flash DSC, the Flash DSC heat flow curve exhibits both the obvious glass transition and crystallization signals marked by $T_{g}$ and $T_{X 1}$.

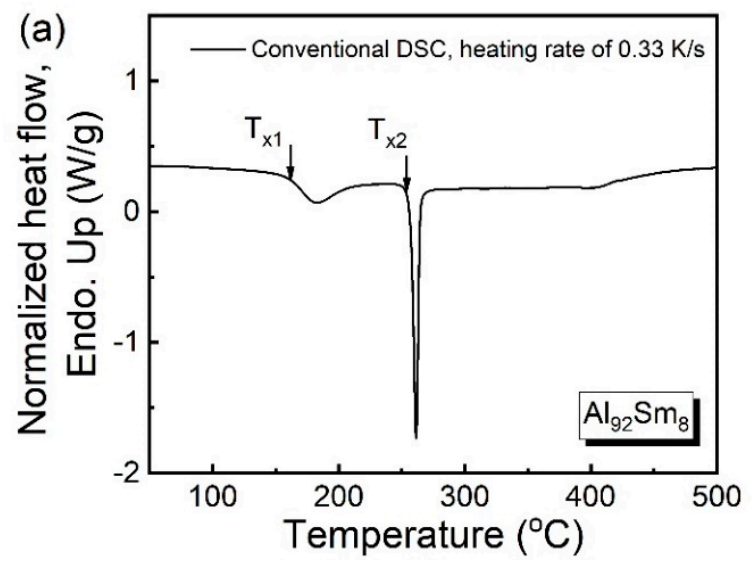

(b)
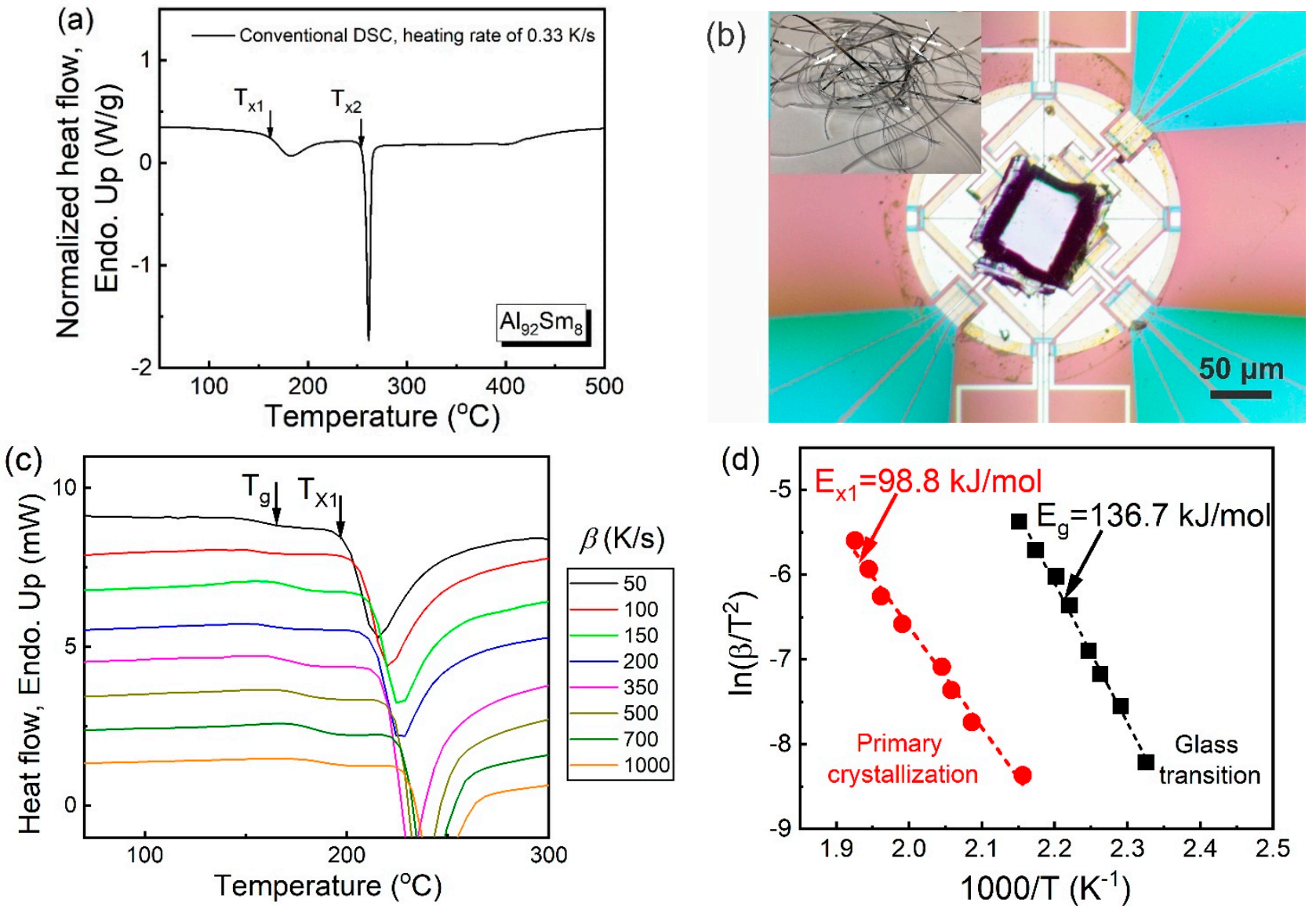

Figure 1. (a) Heat flow curve by conventional DSC with the heating rate of $0.33 \mathrm{~K} / \mathrm{s}$ for $\mathrm{Al}_{92} \mathrm{Sm}_{8} \mathrm{MG}$; (b) optical picture of tiny MG sample on Flash DSC chip (the left inserted picture gives the optical photo of ribbon-like MG sample); (c) a series of Flash DSC heat flow curves by Flash DSC with the heating rates ranging from 50 to $1000 \mathrm{~K} / \mathrm{s}$; and (d) activation energies of glass transition and primary crystallization by fitting the experimental $T_{g}$ and $T_{X 1}$ based on the Kissinger equation.

To further study the dynamic properties of glass transition and primary crystallization for the $\mathrm{Al}_{92} \mathrm{Sm}_{8} \mathrm{MG}$, the evolutions of $T_{g}$ and $T_{X 1}$ with heating rate are analyzed based 
on the Kissinger equation. For MGs, the glass transition temperature and the primary crystallization temperature usually follow the Kissinger equation [7]:

$$
\ln \left(\beta / T^{2}\right)=(-E /(R T))+\text { constant }
$$

where $\beta$ is the heating rate; $T$ is the value of the onset temperature of primary crystallization or the glass transition; $E_{g}$ and $E_{X 1}$ are the activation energies for the glass transition and primary crystallization, respectively; and $R$ is the gas constant. Thus, the activation energy for the glass transition and primary crystallization for $\mathrm{Al}_{92} \mathrm{Sm}_{8} \mathrm{MG}$ can be calculated by fitting the experimental results with Kissinger equation and the detailed results are shown in Figure 1d. The activation energy for primary crystallization is $98.8 \mathrm{~kJ} / \mathrm{mol}$ and $136.7 \mathrm{~kJ} / \mathrm{mol}$ for the glass transition. These activation energy values are comparable with those of previous researches in other Al-based MG systems [10-12]. Thus, for marginal Al-based MG, the glass transition requires more activation energy than that for the primary crystallization process. At a low heating rate in a conventional DSC, the $T_{g}$ signal is superposed by the primary crystallization peak and the weak $T_{g}$ signal is swallowed by the strong crystallization signal. With the increase of heating rates, both $T_{g}$ and $T_{X 1}$ move to higher temperatures. However, $T_{g}$ requires more activation energy to shift, and $T_{g}$ will be left behind by $T_{x}$. Therefore, it is possible to discriminate the two signals and then determine the glass transition temperature for Al-based MGs. This result is consistent with the above-observed glass transition signal in the Flash DSC heat flow curves with a series of fast heating rates in Figure 1c.

\subsubsection{Delay Time Determination in Various Amorphous Materials}

An important application of amorphous materials is to serve as a precursor for the nucleation of crystalline phases that often develop with nanocrystalline sizes. The typical crystallization reaction is illustrated in Figure 2a. Upon isothermal annealing, initially no crystals are present. During this delay time, $\tau$ period crystalline embryos evolve with increasing size towards a critical size range where they can then proceed to grow as crystals. Within this delay time, there is a transient nucleation as the equilibrium cluster size distribution is established to develop into a steady state nucleation rate. The steady state rate continues until a saturation of nucleation sites is reached and is then followed by a size coarsening regime. The transient nucleation rate, $J(t)$, is represented by $[13,14]$.

$$
J(t)=J_{s s} \exp [-\tau / t]
$$

where $t$ is the time and $J_{s s}$ is the homogeneous nucleation that is given by

$$
J_{s s}=\Sigma Z C_{0} \exp \left[-\Delta G^{*} / k T\right]
$$

where $\Sigma$ is the atom attachment frequency to the evolving nucleation clusters, $Z$ is the Zeldovich factor that has a typical value of $0.1, C_{0}$ is the nucleation site density, $\Delta G^{*}$ is the work for nucleus formation, $k$ is the Boltzmann constant, and $T$ is the temperature. Often $\Sigma$ is taken as $D / a^{2}$, where $D$ is the bulk diffusivity and a is the atom spacing. Furthermore, since $D$ is not always available it is estimated from the Stokes-Einstein relation.

$$
D=k T /[6 \pi r \eta]
$$

where $\eta$ is the viscosity and $r$ is the atom size. However, this approach has problems since the bulk diffusivity does not necessarily represent the interface attachment process governing cluster growth, and it has been demonstrated that the Stokes-Einstein relation breaks down near $T_{g}$ [15]. However, from nucleation theory there is a direct relation between $\Sigma$ and $\tau$ given by [14].

$$
\Sigma=1 / 2 \tau Z^{2}
$$



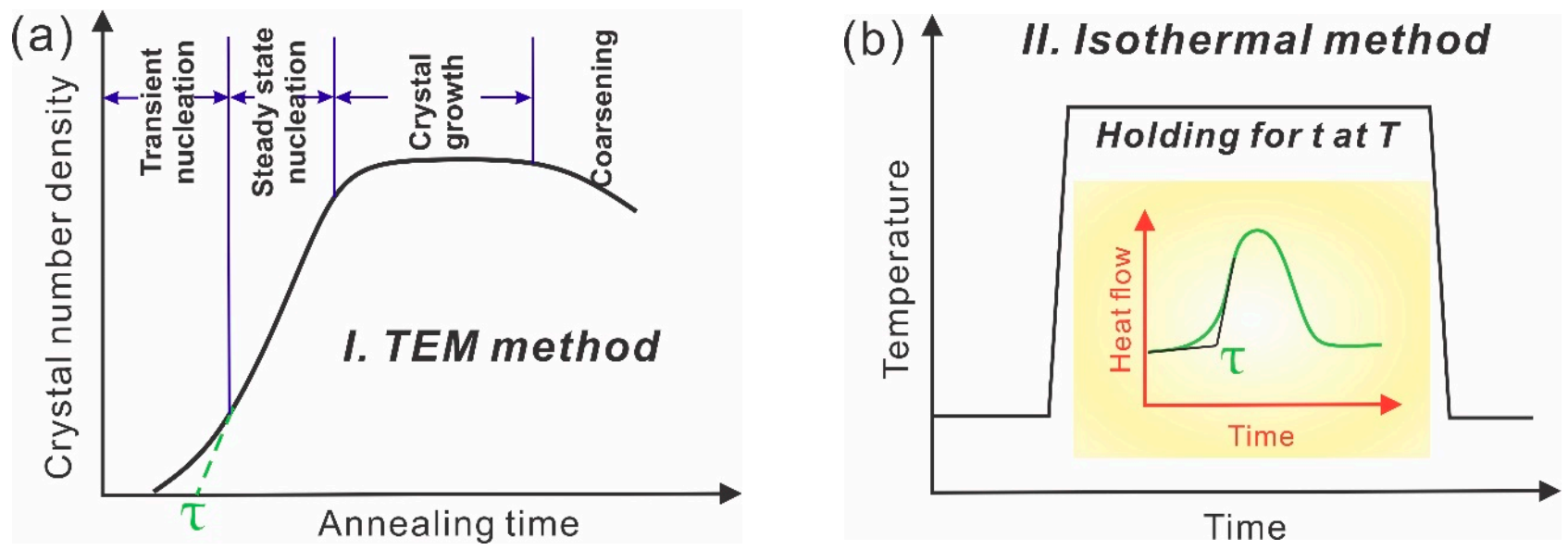

Figure 2. Schemes of traditional experimental methods to determine the delay time $\tau$ for primary crystallization in MGs: (a) TEM method (I); (b) isothermal method based on the thermal tests (II). The inserted graph in (b) gives the confirmation details of delay time by method II.

Thus, a measurement of $\tau$ offers an accurate approach to evaluating $\beta$ and the nucleation rate. Moreover, the magnitude of $\tau$ also provides an effective evaluation of the glass formation ability as large $\tau$ values are necessary for bulk glass formation. For example, a longer delay time at one temperature endows the higher thermal stability and the better glass formation ability, which is critical for developing bulk MGs [15]. Thus, it is of great importance to experimentally and precisely determine the delay time corresponding to different temperatures.

There are two common methods to experimentally measure the delay time for primary crystallization in amorphous materials: I. TEM method by plotting the measured crystal number density and the annealing time at one temperature and then extrapolating the steady state nucleation slope line to the time axis, the delay time can be established (see Figure 2a) [16,17]; II. isothermal test method by holding the amorphous sample at one temperature and then observing the onset time for the crystallization reaction (see Figure 2b) $[18,19]$. For method I, a great deal of TEM sample preparation and testing is required, and thus it is very time-consuming and is not a preferential method. For method II, the crystallization signal should be strong enough to show up in the isothermal annealing DSC trace, which makes it possible to directly measure the delay time for crystallization by isothermal tests. Thus, the amorphous system should have good glass formation ability and thermal stability, such as the Zr-, Pd-, and Ce-based bulk MG systems [18,19]. However, for some marginal amorphous materials, such as the typica marginal Al-based MGs with poor glass formation ability, there usually appears a primary nucleation peak for Al nanocrystals followed by secondary or tertiary crystallization reactions involving intermetallic phases [20]. The signal from the primary nucleation of the precipitation of FCC Al nanocrystals is so weak that the crystallization peak is difficult to detect in the isothermal DSC tests [21]. Therefore, one precise and convenient method would be valuable for the determination of delay time for crystal nucleation in various amorphous materials.

Based on the Flash DSC with ultrafast heating and cooling rates, a new method is demonstrated to decide the delay time for primary crystallization. Under isothermal treatment, the evolution of glass transition temperature with annealing time for amorphous materials should follow two different paths: structural relaxation before the onset of crystal nucleation, and the composition or ordering change after the onset of crystallization. Thus, the break time point in the slope of the plot of the glass transition temperature change with annealing time should correspond to the delay time for the primary crystallization [22,23]. Three different kinds of amorphous systems were selected to verify the effectiveness and universality of the method, including one typical marginal Al-based MG with poor glass formation ability $\left(\mathrm{Al}_{92} \mathrm{Sm}_{8}\right)$, two stable $\mathrm{MG}$ systems with good glass formation 
ability $\left(\mathrm{La}_{60} \mathrm{Ni}_{15} \mathrm{Al}_{25}\right.$ and $\mathrm{Mg}_{65} \mathrm{Cu}_{25} \mathrm{Gd}_{10}$ ), and one amorphous polymer (polybutylene terephthalate, PBT).

\section{(1) Marginal Al-Based MG}

For the conventional DSC with heating rate of several $\mathrm{K} / \mathrm{s}$, the thermal signal of the glass transition for marginal Al-based MGs cannot be detected due to the close overlap of the strong crystallization exotherm. In contrast, the Flash DSC with the large heating rate range from several $\mathrm{K} / \mathrm{s}$ to $10^{4} \mathrm{~K} / \mathrm{s}$ allows for the separation of the $T_{g}$ and $T_{x}$ signals, as described in part Section 3.1.1. Thus, the ultrafast chip calorimetry instrument provides a good opportunity to study the delay time for marginal Al-based MGs. For an $\mathrm{Al}_{92} \mathrm{Sm}_{8}$ MG, a series of Flash DSC heat flow curves with the same heating rate of $1000 \mathrm{~K} / \mathrm{s}$ was measured after annealing at $150{ }^{\circ} \mathrm{C}$ for different times ranging from $20 \mathrm{~s}$ to $10,000 \mathrm{~s}$, as shown in Figure 3a. It is obvious that all of Flash DSC heat flow curves display the obvious endothermic reaction signals corresponding to glass transition and the $T_{g}$ shifts to the higher temperature with the increase of annealing time $t_{a}$. These results are very close to the previous research on the structural relaxation effect on MGs $[24,25]$. To study the evolution of the glass transition temperature $T_{g}$ with annealing time $t_{a}, T_{g}$ is plotted against $t_{a}$ at $150{ }^{\circ} \mathrm{C}$, as shown in the Figure $3 \mathrm{~b}$. From Figure $3 \mathrm{~b}$, it is evident that with the increase of $t_{a}$, there appears one break point at $930 \mathrm{~s}$. Before and after $930 \mathrm{~s}$, the evolution paths of $T_{g}$ with $t_{a}$ can be roughly fitted by two lines with different slopes. These two different evolution paths correspond to the structural relaxation effect and the composition effect, and the samples before and after the break points should be amorphous and contain nanocrystals, respectively [22,23].
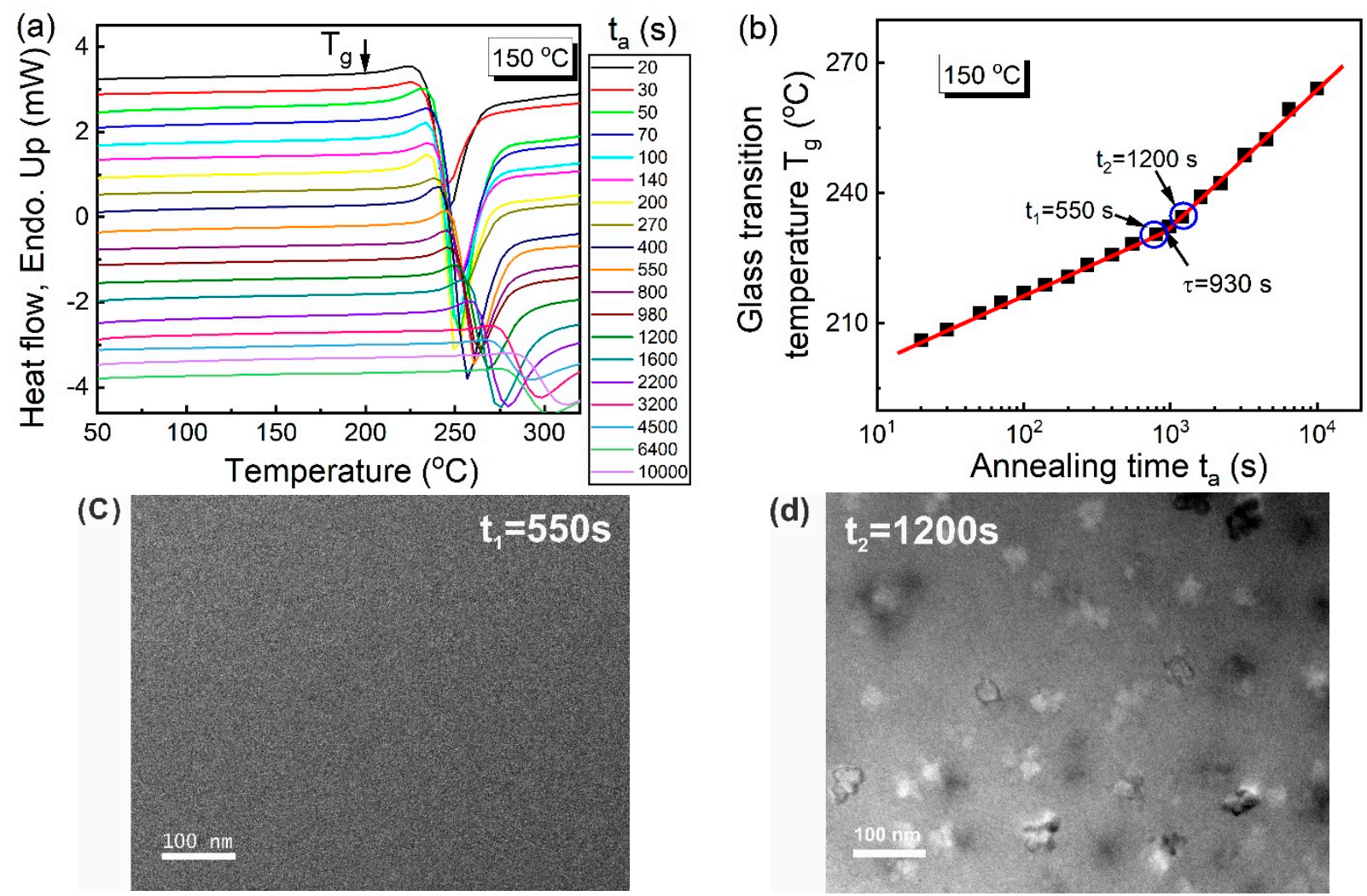

Figure 3. (a) A series of Flash DSC heat flow curves corresponding to different annealing times ranging $t_{a}$ from 20 to $10,000 \mathrm{~s}$ at $150{ }^{\circ} \mathrm{C}$ for $\mathrm{Al}_{92} \mathrm{Sm}_{8} \mathrm{MG}$; (b) plot of $T_{g}$ and $t_{a}$ at $150{ }^{\circ} \mathrm{C}\left(t_{1}\right.$ and $t_{2}$ are two selected annealing times before and after the break point of $930 \mathrm{~s}$ ); (c) TEM image for annealed sample corresponding to the annealing time of $t_{1}$; and (d) TEM image for annealed sample corresponding to the annealing time of $t_{2}$. 
To further test if the delay time for primary crystallization corresponds to the experimental breaking time of glass transition temperature with annealing time, two annealing time points were selected before and after the breaking time, $t_{1}(550 \mathrm{~s})$ and $t_{2}(1200 \mathrm{~s})$. Then, for these two annealed samples by Flash DSC, TEM samples were prepared by FIB methods in order to observe the corresponding crystallization morphology. The corresponding TEM images corresponding to $t_{1}$ and $t_{2}$ are shown in Figure $3 c, d$, respectively. It is evident that at $150{ }^{\circ} \mathrm{C}$, the sample with the annealing time of $550 \mathrm{~s}$ before the break point is still amorphous without any crystals; in contrast, for the samples with the annealing time of $1200 \mathrm{~s}$ after the break point, a great number of nanoscale crystals are observed. Thus, the above results and analyses verify that the break point of $930 \mathrm{~s}$ is actually the delay time at $150{ }^{\circ} \mathrm{C}$ for the $\mathrm{Al}_{92} \mathrm{Sm}_{8} \mathrm{MG}$, which is consistent with previous research [22,23].

(2) Stable La-Based MG

For the stable La-based MG system, the thermal signals for the glass transition and primary crystallization are strong [26]. To verify if the above new method to confirm the delay time for primary crystallization is effective for the La-based MG, one typical composition of $\mathrm{La}_{60} \mathrm{Ni}_{15} \mathrm{Al}_{25}$ was selected and the target temperature was set at $270{ }^{\circ} \mathrm{C}$. Then, a series of Flash DSC heat flow curves corresponding to different annealing times ranging from $1 \mathrm{~s}$ to $50 \mathrm{~s}$ with the heating rate of $500 \mathrm{~K} / \mathrm{s}$ were measured, as shown in Figure 4a. From Figure 4a, the heat flow curves with different annealing times for $\mathrm{La}_{60} \mathrm{Ni}_{15} \mathrm{Al}_{25} \mathrm{MG}$ exhibit the obvious signals of the glass transition and primary crystallization. The onset values of the glass transition obviously shift to the higher temperature range with the increase of the annealing times, which is consistent with the structural relaxation effects in MGs $[24,25]$. Similar to the analyses process for the delay time confirmation method in part (1) for Al-based MG, the onset value of the glass transition $T_{g}$ with the annealing time $t_{a}$ can be plotted as shown in Figure $4 \mathrm{~b}$. From Figure $4 \mathrm{~b}$, it is apparent that with the increase of $t_{a}$ at $270{ }^{\circ} \mathrm{C}$, a break point time appears at $22.5 \mathrm{~s}$. Before and after $22.5 \mathrm{~s}$, the evolution paths of $T_{g}$ with $t_{a}$ can be roughly fitted by two lines with different slopes corresponding to two different governing mechanisms of the structural relaxation and the composition change induced by the crystallization. In comparison, the isothermal method (method II in Figure 2b) was also applied to measure the delay time for $\mathrm{La}_{60} \mathrm{Ni}_{15} \mathrm{Al}_{25} \mathrm{MG}$ sample at $270{ }^{\circ} \mathrm{C}$. The detailed temperature program can be seen in Figure $2 \mathrm{~b}$. As shown in Figure $4 \mathrm{c}$, at $270{ }^{\circ} \mathrm{C}$, when the annealing time increases into about $24 \mathrm{~s}$, the exothermic peak corresponding to the primary crystallization appears. The time of $24 \mathrm{~s}$ is the delay time at $270{ }^{\circ} \mathrm{C}$, which is very close to the experimental data of $22.5 \mathrm{~s}$ by the Flash DSC method.
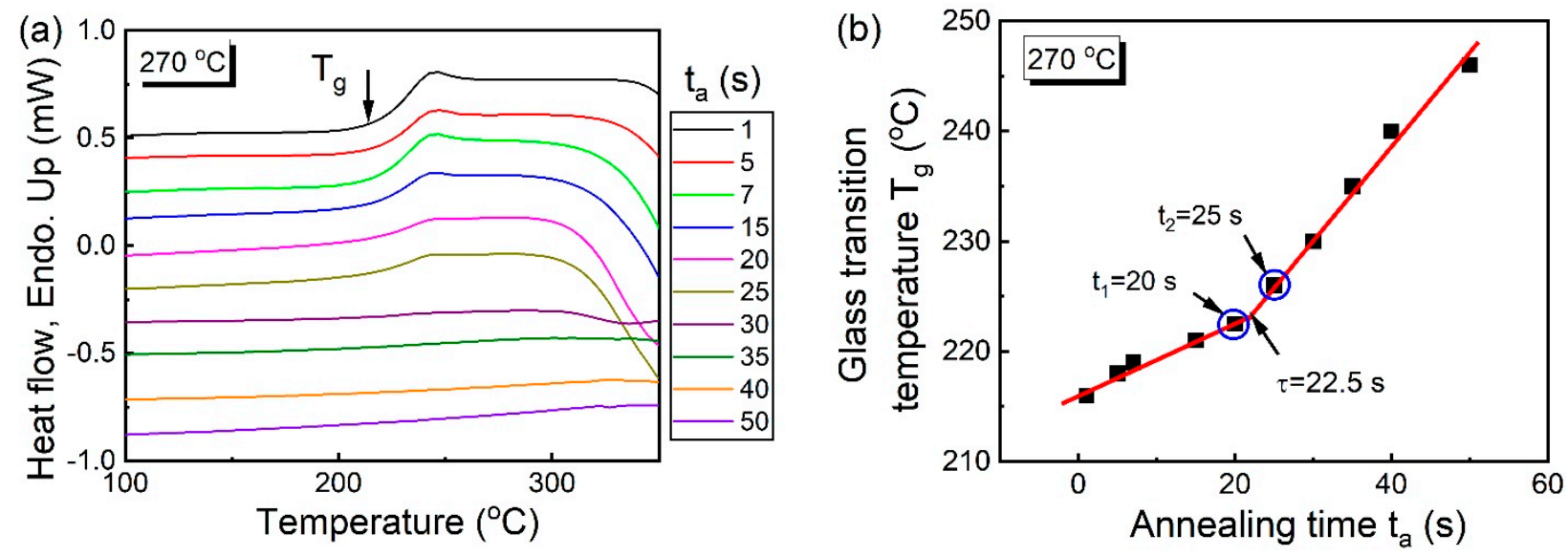
(c)

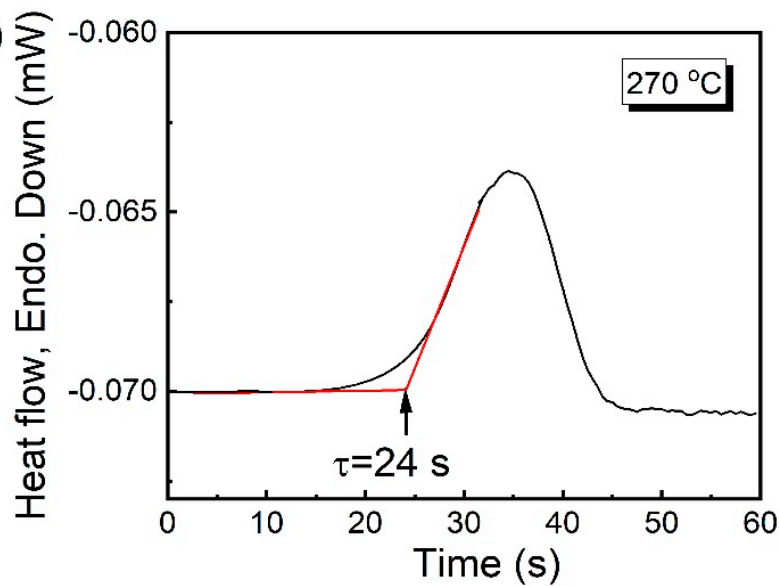

(d)

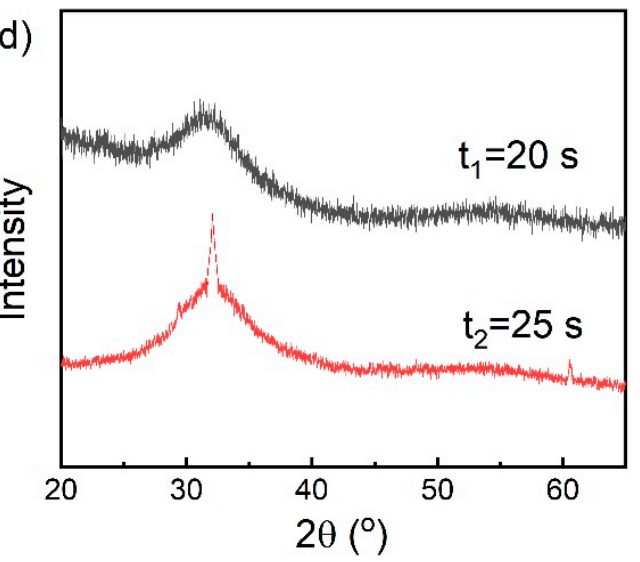

Figure 4. (a) A series of Flash DSC heat flow curves corresponding to different annealing times ranging $t_{a}$ from 1 to $50 \mathrm{~s}$ at $270{ }^{\circ} \mathrm{C}$ for $\mathrm{La}_{60} \mathrm{Ni}_{15} \mathrm{Al}_{25} \mathrm{MG}$; (b) plot of $T_{g}$ and $t_{a}$ at $270{ }^{\circ} \mathrm{C}\left(t_{1}\right.$ and $t_{2}$ are two selected annealing times before and after the break point of $22.5 \mathrm{~s}$ ); (c) the isothermal test for $\mathrm{La}_{60} \mathrm{Ni}_{15} \mathrm{Al}_{25} \mathrm{MG}$ at $270{ }^{\circ} \mathrm{C}$; and (d) XRD patterns for annealed samples corresponding to the annealing times of $t_{1}$ and $t_{2}$.

To confirm if the delay time of the experimental breaking time of glass transition temperature with annealing time in Figure $4 \mathrm{~b}$ corresponds to the onset time for primary crystallization, two annealing time points were selected before and after the break time, $t_{1}(20 \mathrm{~s})$ and $t_{2}(25 \mathrm{~s})$. Then, for these two annealed samples obtained by Flash DSC, XRD tests were conducted to characterize the sample state. The corresponding XRD patterns corresponding to the annealing times of $t_{1}$ and $t_{2}$ are shown in Figure $4 \mathrm{~d}$. It is apparent that at $270{ }^{\circ} \mathrm{C}$, the sample with the annealing time of $20 \mathrm{~s}$ before the break point is still amorphous without any crystals; in contrast, for the samples with the annealing time of $25 \mathrm{~s}$ after the break point time, one sharp crystallization peak was observed, which indicates that the annealed sample is crystallized. Thus, the above results show that the break point time of $22.5 \mathrm{~s}$ is actually the delay time at $270{ }^{\circ} \mathrm{C}$ for the stable $\mathrm{La}_{60} \mathrm{Ni}_{15} \mathrm{Al}_{25} \mathrm{MG}$.

\section{(3) Stable Mg-Based MG}

Similar to the stable La-based MG, the Mg-based MG with a composition of $\mathrm{Mg}_{65} \mathrm{Cu}_{25} \mathrm{Gd}_{10}$ is also one of the typical stable MG systems [27]. As shown in Figure 5a, a series of Flash DSC heat flow curves were obtained corresponding to different annealing times ranging from $5 \mathrm{~s}$ to $60 \mathrm{~s}$ at $200{ }^{\circ} \mathrm{C}$ with the heating rate of $500 \mathrm{~K} / \mathrm{s}$. The heat flow curves with different annealing times for $\mathrm{Mg}_{65} \mathrm{Cu}_{25} \mathrm{Gd}_{10} \mathrm{MG}$ exhibit the clear signals of the glass transition and primary crystallization, which are consistent with the thermal behaviors for La-based MG in part (2). What is more, the $T_{g}$ shifts to the higher temperature with the increase of the annealing time $t_{a}$. Similar to the analyses process for the delay time confirmation method in part (1) for Al-based MG and in part (2) for La-based MG, the onset value of the $T_{g}$ with the annealing time $t_{a}$ can be plotted as shown in Figure $5 \mathrm{~b}$. From Figure $5 \mathrm{~b}$, with the increase of $t_{a}$ at $200^{\circ} \mathrm{C}$, one break point time appears at $33.7 \mathrm{~s}$. Before and after $33.7 \mathrm{~s}$, the evolution paths of $T_{g}$ with $t_{a}$ follow two different paths corresponding to the structural relaxation and the composition effect. Meanwhile, the isothermal method was also applied to measure the delay time for $\mathrm{Mg}_{65} \mathrm{Cu}_{25} \mathrm{Gd}_{10} \mathrm{MG}$ sample at $200^{\circ} \mathrm{C}$. As shown in Figure $5 \mathrm{c}$, at $200{ }^{\circ} \mathrm{C}$, when the annealing time increases to about $35 \mathrm{~s}$, the exothermic peak corresponding to the primary crystallization appears. The time of $35 \mathrm{~s}$ is the delay time at $270{ }^{\circ} \mathrm{C}$, which is very close to the experimental data of $33.7 \mathrm{~s}$ based on the evolution of the glass transition $T_{g}$ with the annealing time $t_{a}$. 

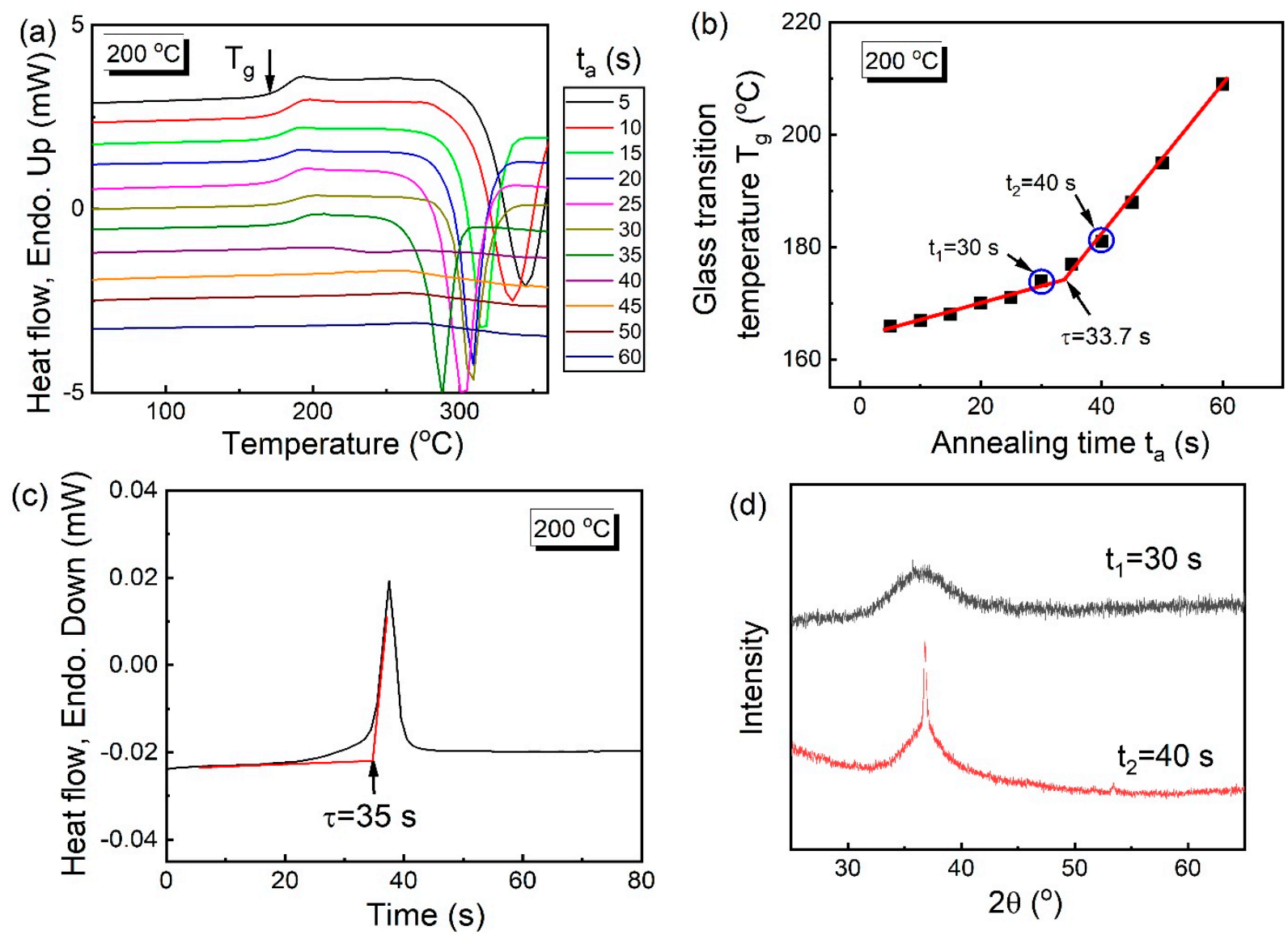

Figure 5. (a) A series of Flash DSC heat flow curves corresponding to different annealing times ranging $t_{a}$ from 5 to $60 \mathrm{~s}$ at $200{ }^{\circ} \mathrm{C}$ for $\mathrm{Mg}_{65} \mathrm{Cu}_{25} \mathrm{Gd}_{10} \mathrm{MG}$; (b) plot of $T_{g}$ and $t_{a}$ at $200{ }^{\circ} \mathrm{C}\left(t_{1}\right.$ and $t_{2}$ are two selected annealing times before and after break point of $33.7 \mathrm{~s}$ ); (c) the isothermal test for $\mathrm{Mg}_{65} \mathrm{Cu}_{25} \mathrm{Gd}_{10} \mathrm{MG}$ at $200{ }^{\circ} \mathrm{C}$; and (d) XRD patterns for annealed samples corresponding to the annealing times of $t_{1}$ and $t_{2}$.

To confirm if the delay time of the experimental breakpoint time by Flash DSC corresponds to the onset time for primary crystallization, two annealing time points were selected before and after the break point time, $t_{1}(30 \mathrm{~s})$ and $t_{2}(40 \mathrm{~s})$. XRD tests for these two annealed samples were conducted. The corresponding XRD patterns corresponding to the annealing times of $t_{1}$ and $t_{2}$ are shown in Figure $5 \mathrm{~d}$. One can see that at $200{ }^{\circ} \mathrm{C}$, the sample with the annealing time of $30 \mathrm{~s}$ before the breakpoint time are still amorphous without any crystals; in contrast, for the samples with the annealing time of $40 \mathrm{~s}$ after the breakpoint time, one sharp crystallization peak is observed. Thus, the above results show that the break point time of $33.7 \mathrm{~s}$ is actually the delay time at $200{ }^{\circ} \mathrm{C}$ for the stable $\mathrm{Mg}_{65} \mathrm{Cu}_{25} \mathrm{Gd}_{10} \mathrm{MG}$.

\section{(4) Amorphous Polymer Material}

To verify if the delay time confirmation method by Flash DSC can be applied for the amorphous polymer materials, one typical amorphous polymer-polybutylene terephthalate (PBT) was chosen for examination $[1,28,29]$. At an annealing temperature of $50{ }^{\circ} \mathrm{C}$, a series of heat flow curves with different annealing times ranging from $2 \mathrm{~s}$ to $12 \mathrm{~s}$ were measured and are shown in Figure 6a. Similar to the MG systems, the glass transition temperature $T_{g}$ for PBT sample also shifts to the higher temperature with the increase of the annealing time $t_{a}$, which indicates the structural relaxation effect. Moreover, the corresponding $T_{g}-t_{a}$ dependence can be plotted in Figure $6 \mathrm{~b}$. When $t_{a}$ increases to about $6.6 \mathrm{~s}$, a break point appears between the two evolution paths. Meanwhile, the isothermal method was also applied to measure the delay time for PBT sample at $50{ }^{\circ} \mathrm{C}$. As shown in Figure $6 \mathrm{c}$, at $50{ }^{\circ} \mathrm{C}$, when the annealing time increases into about $6.3 \mathrm{~s}$, the exothermic peak corresponding to 
the primary crystallization appears. The time of $6.3 \mathrm{~s}$ is the delay time at $50{ }^{\circ} \mathrm{C}$, which is very close to the experimental data of $6.6 \mathrm{~s}$ based on the evolution of the glass transition $T_{g}$ with the annealing time $t_{a}$. By selecting three annealing time points before $\left(t_{1}, 6 \mathrm{~s}\right)$ and after the break point $\left(t_{2}, 8 \mathrm{~s}\right)$, the XRD tests for these two annealed samples were conducted. The annealed samples before and after break point are respectively amorphous and crystalline in Figure $6 \mathrm{~d}$, which confirms the delay time at $50{ }^{\circ} \mathrm{C}$ for the PBT sample. Based on the previous research $[28,29]$, for amorphous polymer materials, with the increase of the annealing time, the crystalline phase gradually grows and the ordering degree within polymer increases. Considering that the polymer is one single composition, the break point for $T_{g}-t_{a}$ plot in amorphous PBT in Figure $6 \mathrm{~b}$ corresponds to the transition from the relaxation effect to the ordering effect.
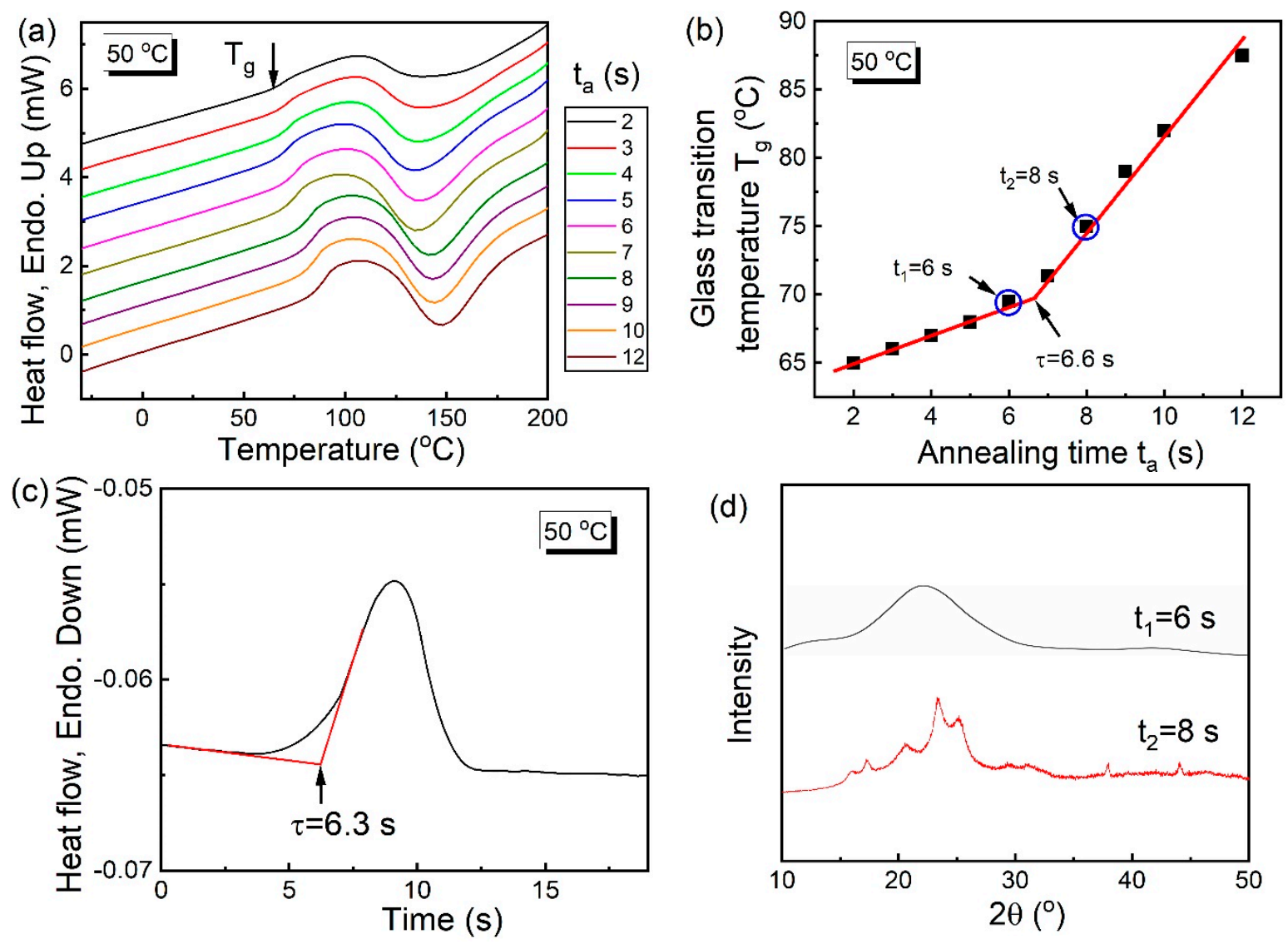

Figure 6. (a) A series of Flash DSC heat flow curves corresponding to different annealing times ranging $t_{a}$ from 2 to $12 \mathrm{~s}$ at $50{ }^{\circ} \mathrm{C}$ for amorphous PBT sample; (b) plot of $T_{g}$ and $t_{a}$ at $50{ }^{\circ} \mathrm{C}\left(t_{1}\right.$ and $t_{2}$ are two selected annealing times before and after the break point of $6.6 \mathrm{~s}$ ); (c) the isothermal test for PBT sample at $50{ }^{\circ} \mathrm{C}$; and (d) XRD patterns for annealed samples corresponding to the annealing times of $t_{1}$ and $t_{2}$.

Based on the above results and discussions in parts (1)-(4), the experimental method to determine the delay time for primary crystallization based on the chip calorimetry is an effective method for various amorphous materials, which provides a good opportunity to investigate the nucleation and crystallization behaviors in glassy materials.

\subsection{Glass Formation}

\subsubsection{New Polyamorphous Material-D-Mannitol}

Polyamorphism refers to the existence of two amorphous phases of the same composition separated by a first-order transition. This phenomenon is analogous to crystal polymorphism exemplified by diamond and graphite but is less well understood and even controversial [30]. Zhu et al. reported that the melt-quenched glass of D-mannitol 
can transit into another apparently amorphous state by continuous heating or isothermal annealing, with a first-order characteristic [2]. In agreement with this report, the first-order transition can be completed by annealing the melt-quenched sample at $310 \mathrm{~K}$ for $180 \mathrm{~s}$ in the conventional DSC. Figure 7a shows when heating the melt-quenched glass (GN) sample with a $20 \mathrm{~K} / \mathrm{min}$ heating rate, the sample begins the glass transition to a supercooled liquid (SCL-1) at $287 \mathrm{~K}$, but further heating results in an exothermic transition from SCL-1 to amorphous phase X (GX) beginning at $298 \mathrm{~K}$. When heating a sample that has been aged at $310 \mathrm{~K}$ for $180 \mathrm{~s}$, the sample shows neither a glass transition at $287 \mathrm{~K}$ nor a sharp exothermic peak at $298 \mathrm{~K} \mathrm{[3].} \mathrm{This} \mathrm{is} \mathrm{identical} \mathrm{to} \mathrm{the} \mathrm{DSC} \mathrm{heating} \mathrm{trace} \mathrm{of} \mathrm{the} \mathrm{GX} \mathrm{sample,} \mathrm{which} \mathrm{is}$ obtained by first being heated to $313 \mathrm{~K}$ (above the first exothermic transition) and then quenched [2].
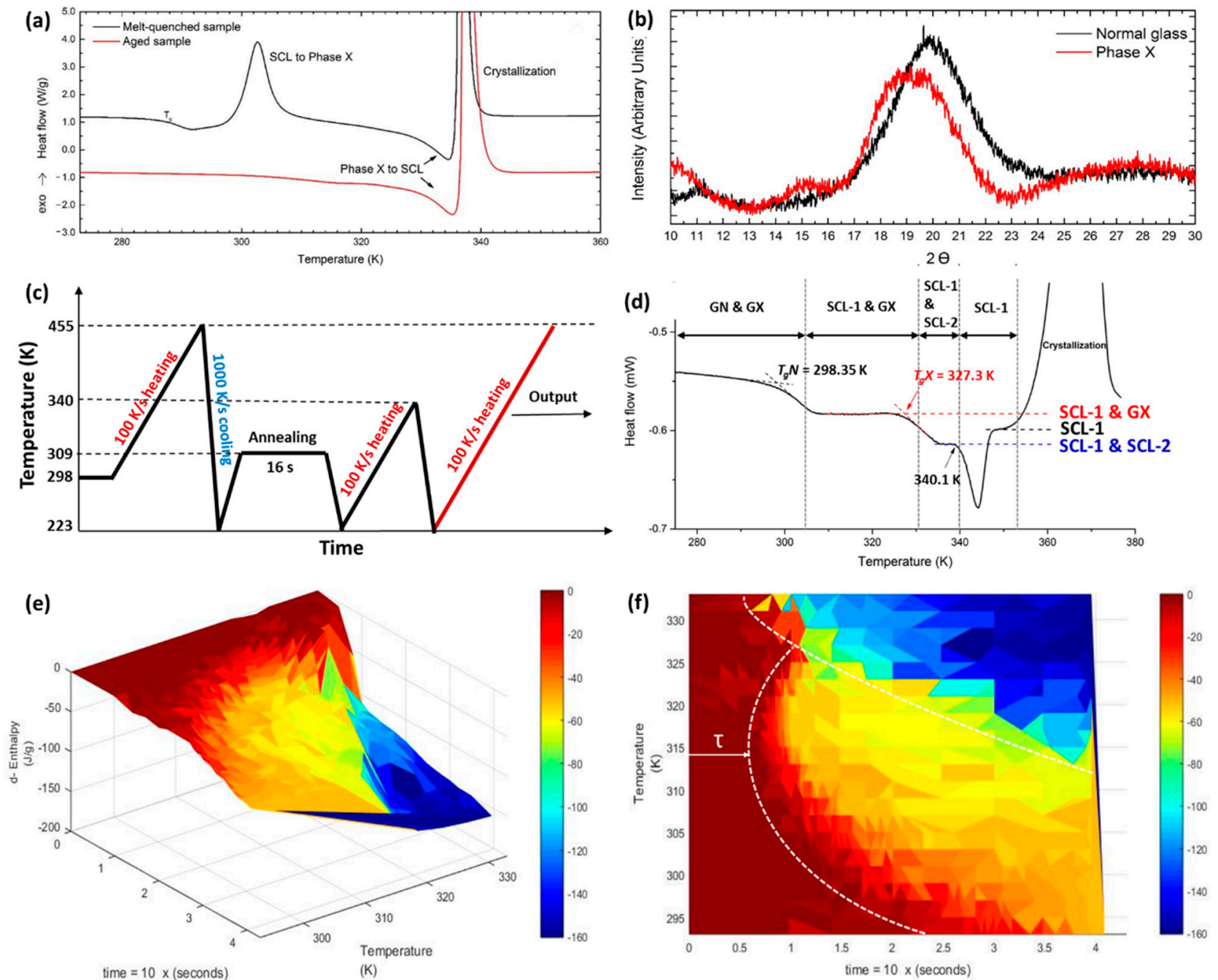

Figure 7. (a) Conventional DSC measurements on a normal glass (GN) and a phase X (GX) D-mannitol sample [31-33]. (b) X-ray diffraction patterns of GN and GX [31,33]. (c) The experimental protocol for the sample preparation in (d). (d) Transition path during heating. Sample was annealed at $309 \mathrm{~K}$ for $16 \mathrm{~s}$, preheated to $340 \mathrm{~K}$, and quenched down before this heating. Sample starts as a mixture of normal (melt-quenched) glass and phase $X$, and shows three endothermic transitions: (1) glass transition of GN (298 K); (2) glass transition of GX (328 K); and (3) liquid-liquid from SCL-2 to SCL-1 $(340 \mathrm{~K})[33]$. (e,f) Enthalpy change with different annealing conditions; (e) is 3-D plot of the enthalpy change with $T_{a}$ and $\ln \left(t_{a}\right) ;(\mathbf{f})$ is the result of projecting the profile onto T-t plane, and the boundaries between adjacent plateaus are the Time-Temperature-Transition curves of the corresponding transition [33].

The X-ray diffraction patterns of GN, GX, and the $\alpha$ crystal polymorph are shown in Figure 7b. It is evident that GX does not have crystal-like diffraction features, which 
strongly indicates that the GX is an amorphous state. Additionally, the diffraction pattern of GX is distinct from that of GN. The GX has a featured broad maximum that appears at lower $2 \theta$ than that for the GN, with an additional small peak around 15 , which likely results from a different local structure with long range correlation. This is consistent with the report that the GN has a smaller specific volume than GX at $273 \mathrm{~K}$, which is the measuring temperature of the $\mathrm{X}$-ray diffraction experiments $[3,4]$.

Due to the slow heating rates of the conventional DSC, GX can form from SCL-1 of GN to produce an exothermic peak. In the Flash-DSC, however, the $100 \mathrm{~K} / \mathrm{s}$ or even a $10 \mathrm{~K} / \mathrm{s}$ heating rate is too fast to allow for this transition so that no exothermic peak can be observed on the heating trace of a melt-quenched GN sample. On the other hand, if the GN sample is annealed with a combination of annealing temperature that can trigger the GN/SCL-1 to GX transition and annealing time that is longer than the delay time of the transition, GX can be formed in the annealed sample and the glass transition of GX can appear in the following heating trace.

An example of that protocol is shown in Figure 7c. After annealing at $T_{a}=309 \mathrm{~K}$ for $t_{a}=16 \mathrm{~s}$, the sample is then reheated to $340 \mathrm{~K}$ to obtain the supercooled liquid state and immediately quenched. The following heating trace in Figure $7 \mathrm{~d}$ clearly shows three endothermic transitions before crystallization as $T_{g}$ of GN at $298.3 \mathrm{~K}, T_{g}$ of GX at $327.3 \mathrm{~K}$, and the transition from SCL-2 to SCL-1 at $340.1 \mathrm{~K}$. It is also worth noting that the mixture of SCL-1 and SCL-2 has a larger specific heat capacity than that for pure SCL-1, which means that pure SCL-2 has a larger specific heat value compared to pure SCL-1 [4].

By choosing the Flash-DSC heating trace of the unannealed GN sample as a baseline that is subtracted from each of the annealing traces, the enthalpy changes under each annealing condition can then be calculated by integrating the remaining curve from Ta to $458 \mathrm{~K}$. By normalizing the enthalpy change with the corresponding sample weight, a three-dimensional plot of the enthalpy change with $T_{a}$ and $\ln \left(t_{a}\right)$ can be constructed as shown in Figure 7e. There are three plateaus in the 3-D profile, which correspond to unannealed GN/SCL-1 $(\Delta H=0 \mathrm{~J} / \mathrm{g}$ red), GX/SCL-2 $(\Delta H=-50$ to $-65 \mathrm{~J} / \mathrm{g}$, yellow and orange), and $\alpha$ crystalline ( $\Delta H=-160 \mathrm{~J} / \mathrm{g}$, blue), respectively. Figure $7 \mathrm{f}$ is obtained by projecting the three-dimensional surface onto the $T-\ln (t)$ plane. In this projection, the boundaries between adjacent plateaus are actually the Time-Temperature-Transition (TTT) curve. The transition boundary between the two amorphous states has a $C$ shape, which is a main feature of thermally activated phase transitions. As a consequence, the time length to reach the boundary at a certain temperature is the delay time $\tau$ for the reaction. It can also be seen that, although the difference is not very large, the height of the plateau corresponding to GX formed at lower annealing temperature (below $305 \mathrm{~K}$ ) is greater than that formed at higher annealing temperature [4].

\subsubsection{In-Situ Formation of Glass in Liquid Crystals}

Liquid crystals (LCs) usually are known to undergo rapid ordering transitions with virtually no hysteresis. These transitions are so fast that almost no supercooling can be observed under ordinary conditions. This allows LCs to serve as standards for temperature calibration at fast cooling rates (up to $2 \times 10^{4} \mathrm{~K} / \mathrm{s}$ ) [31,32]. Recently, ITZ was reported as an exceptional case. At slow cooling, the isotropic liquid transforms to a nematic phase and then to a smectic phase, but at fast cooling, smectic ordering can be avoided altogether or avoided partially to produce glassy solids with variable smectic order [5]. To exhibit the smectic ordering in an equilibrium liquid of ITZ, Figure 8a shows that the isotropic liquid of ITZ transforms to a nematic phase $\left(T_{N / I}=363 \mathrm{~K}\right)$ and then to a smectic phase $\left(T_{S m / N}=347 \mathrm{~K}\right)$ [33-35]. In the nematic phase, the molecules are aligned with their long axes approximately parallel to each other, while in the smectic phase, the molecules are further organized into layers [5]. Further cooling transforms the smectic liquid to a glassy solid $\left(T_{g}=328 \mathrm{~K}\right)$. Upon reheating, the transitions noted above are reversible. 


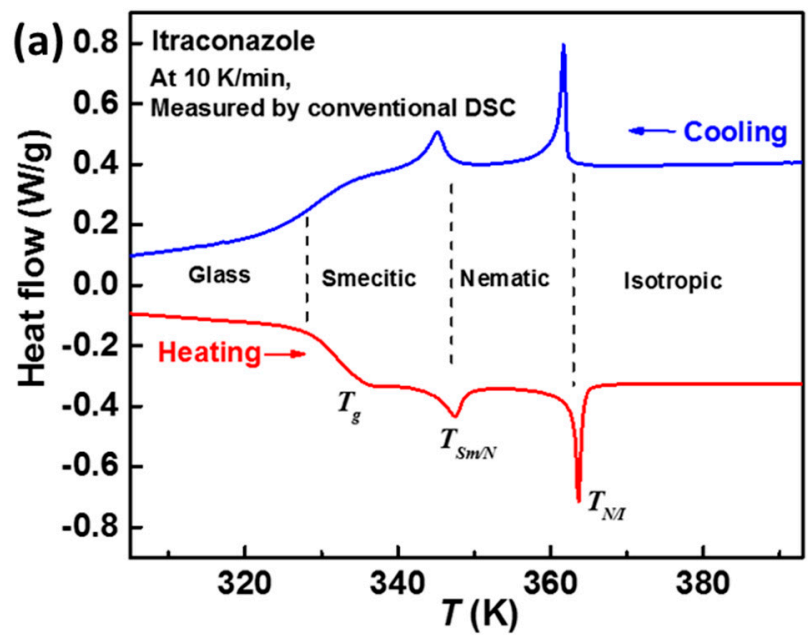

(b)
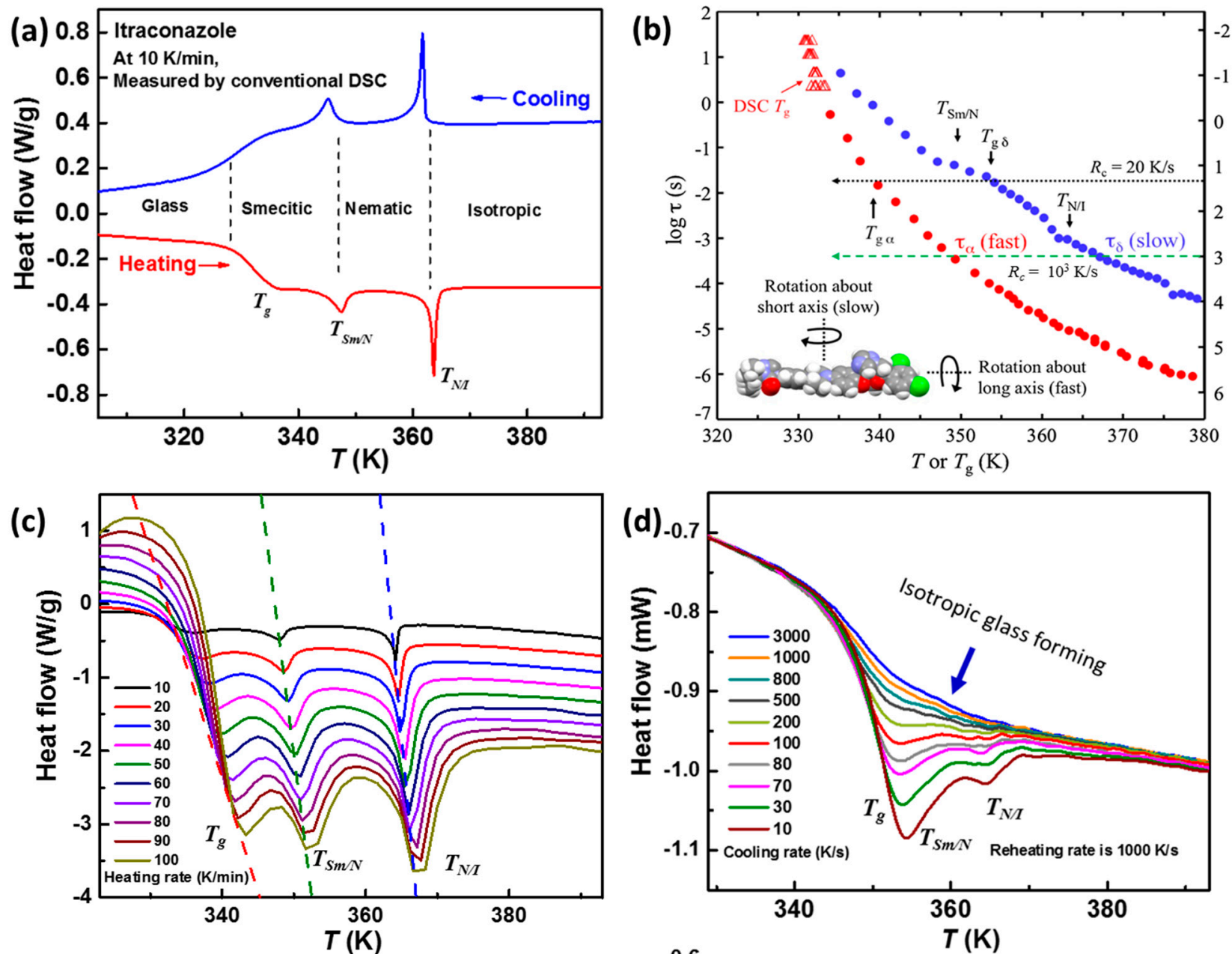

(e)
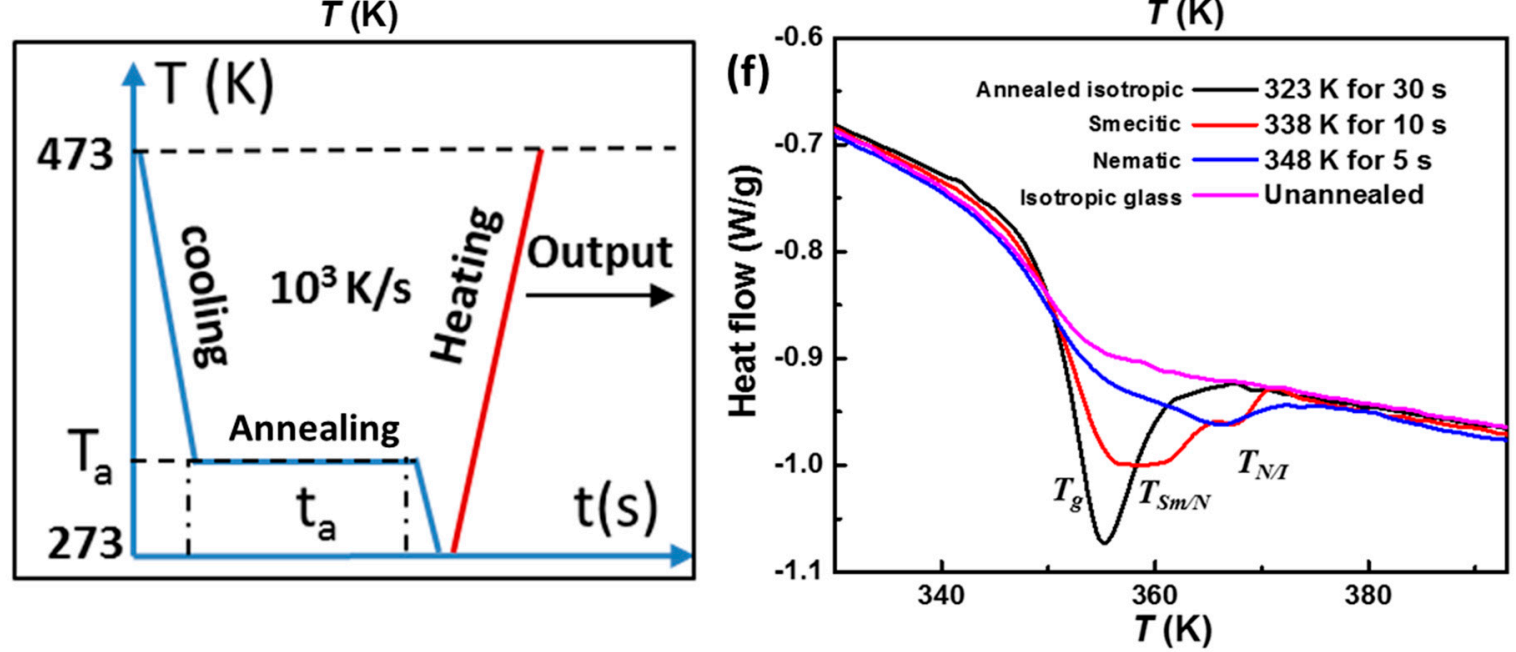

Figure 8. (a) Conventional DSC traces of ITZ during cooling and reheating at $10 \mathrm{~K} / \mathrm{min}$. (b) Fast (red circles) and slow (blue circles) relaxation processes in ITZ from dielectric spectroscopy from Ref. [34], and conventional DSC $T_{g}$ onset (triangle) is shown as a function of cooling rate $R_{\mathcal{C}}$ (right axis) [5,34]. (c) A series of conventional DSC reheating traces with different heating rates, starting from the melt quenched ITZ glass at $10 \mathrm{~K} / \mathrm{min}$ cooling rate. (d) Flash DSC reheating curves with $10^{3} \mathrm{~K} / \mathrm{s}$ heating rate, and the measured ITZ glass formed upon a series of cooling rates from 10 to $3 \times 10^{3} \mathrm{~K} / \mathrm{s}$. (e) The experimental protocol for the different ITZ glass formation in (f). (f) Flash DSC reheating curves at $10^{3} \mathrm{~K} / \mathrm{s}$ heating rate, to examine the ITZ glassy state after the different annealing conditions.

At different cooling rates $\left(R_{\mathcal{c}}\right)$, ITZ glasses can be prepared with and without smectic order. When the cooling rate is faster than the relaxation of nematic to smectic transition 
$\left(R_{c}>20 \mathrm{~K} / \mathrm{s}\right)$, ITZ can be free of smectic order [5]. The rates of molecular rotations in a liquid crystal can be obtained by dielectric spectroscopy, as shown in Figure 8b [36]. Similar to other LCs [37-39], ITZ shows two relaxation processes [34,40]. The fast process has been associated with the glass transition detected by DSC [34,38] and is termed the $\alpha$ process, where the $R_{c}$ value for glass formation is given by the right axis in Figure $8 \mathrm{~b}$. This process is attributed to molecular rotation about the long axis and precession of the long axis about the nematic director, whereas the slow process (called the $\delta$ mode) is attributed to molecular rotation about the short axis (end over end). The rates of the two processes can be significantly different in a liquid crystal; this is a result of a nematic potential that favors the alignment of the long axis along the director and reduces the average rate of end-over-end rotation [5].

From Figure $8 \mathrm{~b}$, it is evident that if $R_{c}>10^{3} \mathrm{~K} / \mathrm{s}$, which is even faster than the rate of the isotropic to nematic transition, the two LC transitions will be avoided, and the liquid can be directly quenched into glassy state. Therefore, to obtain the isotropic glass, the molten sample was quenched at a series of cooling rate from 10 to $10^{4} \mathrm{~K} / \mathrm{s}$ and then reheated at $10^{3} \mathrm{~K} / \mathrm{s}$ to determine the different quenched glassy state structures. Unlike the heating curve measured by conventional DSC as shown in Figure 8a, at a high heating rate under Flash DSC the peak of glass transition overlaps with the peak of the smectic to nematic transition. The evolution of the profile of heating curve is guided by the dash line shown in Figure 8c. Even at the low heating rates from 10 to $100 \mathrm{~K} / \mathrm{min}$ under conventional DSC, the endothermic hump signal of $T_{g}$ shows the obvious tendency to merge with the peak of $T_{S m / N}$ while the distance between the peaks of $T_{S m / N}$ and $T_{N / I}$ stays almost the same. Meanwhile, the profile of the peaks gradually smoothes with increasing heating rate. Therefore, for Flash DSC measurements seen in Figure 8d, the reheating curves upon slow cooling $\left(R_{c}<100 \mathrm{~K} / \mathrm{s}\right)$ show two apparent peaks related to the overlapped $T_{g}$ with $T_{S m / N}$ and the small one about $T_{N / /}$. Consistent with the relaxation process in Figure $8 \mathrm{~b}[5,34]$, upon cooling at $R_{c}>500 \mathrm{~K} / \mathrm{s}$ in Figure $8 \mathrm{~d}$, there is only the glass transition without the signal of the LC transitions, which indicates that the isotropic to nematic transition was avoided during this fast cooling process to form the isotropic ITZ glass.

Since the highly disordered isotropic glass can be formed upon $10^{3} \mathrm{~K} / \mathrm{s}$ quenching, to obtain more kinds of ITZ glass, we conducted annealing treatments on the as-quenched sample according to the protocol shown in Figure 8e. The sample was annealed at $323 \mathrm{~K}$ $\left(T_{a}>T_{g}\right), 338 \mathrm{~K}\left(T_{g}<T_{a}<T_{S m / N}\right)$ and $348 \mathrm{~K}\left(T_{S m / N}<T_{a}<T_{N / I}\right)$ for sufficient time according to the relaxation process $[5,34]$, respectively. As a result, in Figure $8 \mathrm{f}$ the reheating curve of the sample annealed below $T_{g}$ only shows one deep endothermic peak due to the aging effect of the glass, which indicates that there was no apparent smectic or nematic order formed during annealing and sample remained in the isotropic glassy state. For the higher $T_{a}$ annealed samples, the red curve shows both endothermic peaks of the overlapped $T_{g}$ with $T_{S m / N}$ and then $T_{N / I}$ indicating the formation of smectic layers during annealing. The blue curve only shows the obvious $T_{N / I}$ and the weaker signal of $T_{g}$ with $T_{S m / N}$ as a shoulder, indicating that the nematic to isotropic transition dominates in this heating process. Therefore, upon in-situ annealing the various LC orders can be effectively trapped in a glass at a $10^{3} \mathrm{~K} / \mathrm{s}$ cooling rate.

\section{Conclusions}

In this work, recent work is highlighted on nucleation and glass formation by chip calorimetry with ultrafast heating and cooling rate. First, for the marginal Al-based MG system, based on the separated evolution of glass transition and primary crystallization with heating rates, the glass transition signal is successfully separated from primary crystallization within a huge heating rate range. Second, it is an effective and universal method to experimentally determine the nucleation delay time of primary crystallization based on the chip calorimetry platform. This method has been verified to be applied for various amorphous materials, including the marginal MG system, the stable MG systems, and the amorphous polymer system. Third, results from flash DSC experiments provided 
insights into the characteristics of the amorphous-amorphous transition; in particular, the precise annealing conditions that could be reached by flash DSC enabled the construction of the Temperature-Time-Transformation (TTT) plot of D-mannitol for the transition between GN/SCL-1 and GX/SCL-2, as well as the transition between amorphous and crystalline phases revealing thermally activated behavior. Fourth, for LC material ITZ, upon in-situ annealing the various LC orders can be effectively trapped in a glass at a high cooling rate.

Author Contributions: Conceptualization, M.G., C.C. and J.H.P.; methodology, M.G. and C.C.; software, M.G. and C.C.; validation, M.G., C.C. and J.H.P.; formal analysis, M.G., C.C. and J.H.P.; writing-original draft preparation, M.G., C.C. and J.H.P.; writing—review and editing, M.G., C.C. and J.H.P.; visualization, M.G., C.C. and J.H.P.; supervision, J.H.P.; project administration, J.H.P.; funding acquisition, J.H.P. All authors have read and agreed to the published version of the manuscript.

Funding: This research was funded by the Office of Naval Research (N00014-20-1-2704) and NSF (UW-Madison MRSEC DMR 1720415).

Institutional Review Board Statement: Not applicable.

Informed Consent Statement: Not applicable.

Data Availability Statement: The datasets generated during and/or analyzed during the current study are available from the corresponding author on reasonable request.

Conflicts of Interest: The authors declare no conflict of interest.

\section{References}

1. Schawe, J.E.K. Influence of processing conditions on polymer crystallization measured by fast scanning DSC. J. Therm. Anal. Calorim. 2013, 116, 1165-1173. [CrossRef]

2. Zhu, M.; Wang, J.-Q.; Perepezko, J.H.; Yu, L. Possible existence of two amorphous phases of d-mannitol related by a first-order transition. J. Chem. Phys. 2015, 142, 244504. [CrossRef] [PubMed]

3. Zhu, M.; Yu, L. Polyamorphism of D-mannitol. J. Chem. Phys. 2017, 146, 244503. [CrossRef] [PubMed]

4. Tang, W.; Perepezko, J.H. Polyamorphism and liquid-liquid transformations in D-mannitol. J. Chem. Phys. 2018, 149, 074505. [CrossRef] [PubMed]

5. Teerakapibal, R.; Huang, C.; Gujral, A.; Ediger, M.D.; Yu, L. Organic Glasses with Tunable Liquid-Crystalline Order. Phys. Rev. Lett. 2018, 120, 055502. [CrossRef] [PubMed]

6. Bondi, K.; Gangopadhyay, A.; Marine, Z.; Kim, T.; Mukhopadhyay, A.; Goldman, A.; Buhro, W.E.; Kelton, K. Effects of microalloying with 3D transition metals on glass formation in AlYFe alloys. J. Non-Crystalline Solids 2007, 353, $4723-4731$. [CrossRef]

7. Shen, Y.; Perepezko, J.H. Al-based amorphous alloys: Glass-forming ability, crystallization behavior and effects of minor alloying additions. J. Alloy. Compd. 2017, 707,3-11. [CrossRef]

8. Zhuravlev, E.; Schick, C. Fast scanning power compensated differential scanning nano-calorimeter: 1. The device. Thermochim. Acta 2010, 505, 1-13. [CrossRef]

9. Zhuravlev, E.; Schick, C. Fast scanning power compensated differential scanning nano-calorimeter: 2. Heat capacity analysis. Thermochim. Acta 2010, 505, 14-21. [CrossRef]

10. Inoue, A.; Matsumoto, N.; Masumoto, T. Al-Ni-Y-Co Amorphous Alloys with High Mechanical Strengths, Wide Supercooled Liquid Region and Large Glass-Forming Capacity. Mater. Trans. JIM 1990, 31, 493-500. [CrossRef]

11. Ye, F.; Lu, K. Crystallization kinetics of Al-La-Ni amorphous alloy. J. Non Cryst. Solids 2000, 262, 228-235. [CrossRef]

12. Wang, J.Q.; Liu, Y.H.; Imhoff, S.; Chen, N.; Louzguine-Luzgin, D.V.; Takeuchi, A.; Chen, M.W.; Kato, H.; Perepezko, J.H.; Inoue, A. Enhance the thermal stability and glass forming ability of Al-based metallic glass by Ca minor-alloying. Intermetallics 2012, 29, 35-40. [CrossRef]

13. Kelton, K.F.; Greer, A.L. Transient nucleation effects in glass formation. J. Non Cryst. Solids 1986, 79, 295-309. [CrossRef]

14. Fokin, V.M.; Kalinina, A.M.; Filipovich, V.N. Nucleation in silicate glasses and effect of preliminary heat treatment on it. J. Cryst. Growth 1981, 52, 115-121. [CrossRef]

15. Lu, Z.P.; Liu, C.T. A new glass-forming ability criterion for bulk metallic glasses. Acta Mater. 2002, 50, 3501-3512. [CrossRef]

16. Perepezko, J.H. Nucleation-controlled reactions and metastable structures. Prog. Mater. Sci. 2004, 49, 263-284. [CrossRef]

17. Perepezko, J.H.; Imhoff, S.D. Primary crystallization reactions in Al-based metallic glass alloys. J. Alloys Compd. 2010, 504, S222-S225. [CrossRef]

18. Zhang, B.; Zhao, D.Q.; Pan, M.X.; Wang, W.H.; Greer, A.L. Amorphous Metallic Plastic. Phys. Rev. Lett. 2005, 94, 205502. [CrossRef]

19. Johnson, W.L. Bulk Glass-Forming Metallic Alloys: Science and Technology. MRS Bull. 1999, 24, 42-56. [CrossRef] 
20. Shen, Y.; Perepezko, J.H. The effect of minor addition of insoluble elements on transformation kinetics in amorphous Al alloys. J. Alloys. Compd. 2015, 643, S260-S264. [CrossRef]

21. Xing, L.Q.; Mukhopadhyay, A.; Buhro, W.E.; Kelton, K.F. Improved Al-Y-Fe glass formation by microalloying with Ti. Philos. Mag. Lett 2004, 84, 293-302. [CrossRef]

22. Shen, Y.; Perepezko, J.H. Investigation of the nucleation delay time in Al-based metallic glasses by high rate calorimetry. J. Non Cryst. Solids 2018, 502, 9-14. [CrossRef]

23. Gao, M.; Perepezko, J.H. Flash DSC determination of the delay time for primary crystallization and minor alloying effect in marginal Al-based metallic glasses. Thermochim. Acta 2019, 677, 91-98. [CrossRef]

24. Slipenyuk, A.; Eckert, J. Correlation between enthalpy change and free volume reduction during structural relaxation of Zr55Cu30Al10Ni5 metallic glass. Scr. Mater. 2004, 50, 39-441. [CrossRef]

25. Mei, J.N.; Soubeyroux, J.L.; Blandin, J.J.; Li, J.S.; Kou, H.C.; Fu, H.Z.; Zhou, L. Structural relaxation of Ti40Zr25Ni8Cu9Be18 bulk metallic glass. J. Non Cryst. Solids 2011, 357, 110-1151. [CrossRef]

26. Qiao, J.C.; Pelletier, J.M.; Blandin, J.J.; Gravier, S. High temperature deformation in a lanthanum based bulk metallic glass showing a pronounced secondary relaxation. Mater. Sci. Eng. A 2013, 586, 57-61. [CrossRef]

27. Men, H.; Kim, D.H. Fabrication of ternary Mg-Cu-Gd bulk metallic glass with high glass-forming ability under air atmosphere. J. Mater. Res. 2003, 18, 1502-1504. [CrossRef]

28. Mileva, D.; Androsch, R.; Zhuravlev, E.; Schick, C.; Wunderlich, B. Homogeneous nucleation and mesophase formation in glassy isotactic polypropylene. Polymer 2012, 53, 277-282. [CrossRef]

29. Onishi, Y.; Nakai, T. Effect of nucleation of Poly (1,4-butylene terephthalate) on its flowability. Polymer J. Calorim. 1992, 24, 833-840. [CrossRef]

30. Tanaka, H. Importance of many-body orientational correlations in the physical description of liquids. Faraday Discuss. 2013, 167, 9-76. [CrossRef]

31. Wouters, S.; Demir, F.; Beenaerts, L.; Van Assche, G. Calibration and performance of a fast-scanning DSC-Project RHC. Thermochim. Acta 2012, 530, 64-72. [CrossRef]

32. Jiang, J.; Zhuravlev, E.; Huang, Z.; Wei, L.; Xu, Q.; Shan, M.; Xue, G.; Zhou, D.; Schick, C.; Jiang, W. A transient polymorph transition of 4-cyano-4'-octyloxybiphenyl (8OCB) revealed by ultrafast differential scanning calorimetry (UFDSC). Soft Matter. 2013, 9, 1488-1491. [CrossRef]

33. Six, K.; Verreck, G.; Peeters, J.; Binnemans, K.; Berghmans, H.; Augustijns, P.; Kinget, R.; Mooter, G.V.D. Investigation of thermal properties of glassy itraconazole: Identification of a monotropic mesophase. Thermochim. Acta 2001, 376, 175-181. [CrossRef]

34. Tarnacka, M.; Adrjanowicz, K.; Kaminska, E.; Kaminski, K.; Grzybowska, K.; Kolodziejczyk, K.; Wlodarczyk, P.; Hawelek, L.; Garbacz, G.; Kocot, A.; et al. Molecular dynamics of itraconazole at ambient and high pressure. Phys. Chem. Chem. Phys. 2013, 15, 20742-20752. [CrossRef] [PubMed]

35. Ramos, J.J.M.; Diogo, H.P. The slow relaxation dynamics in active pharmaceutical ingredients studied by DSC and TSDC: Voriconazole, miconazole and itraconazole. Int. J. Pharmacol. 2016, 501, 39-48. [CrossRef] [PubMed]

36. Broadband Dielectric Spectroscopy; Kremer, F.; Schönhals, A. (Eds.) Springer: Berlin, Germany, 2003.

37. González, Y.; Palacios, B.; Jubindo, M.A.P.; de la Fuente, M.R.; Serrano, J.L. Dielectric relaxation study in a glassy low-molecularweight ferroelectric liquid crystal. Phys. Rev. E 1995, 52, R5764. [CrossRef]

38. Brás, A.R.; Dionísio, M.; Huth, H.; Schick, C.; Schönhals, A. Origin of glassy dynamics in a liquid crystal studied by broadband dielectric and specific heat spectroscopy. Phys. Rev. E 2007, 75, 061708. [CrossRef]

39. Schönhals, A.; Zubowa, H.L.; Fricke, R.; Frunza, S.; Frunza, L.; Moldovan, R. On the Dielectric Behavior of Unaligned Samples of 4-n-Octyl-4'-cyanobiphenyl (8CB). Cryst. Res. Technol. 1999, 34, 1309. [CrossRef]

40. Mapesa, E.U.; Tarnacka, M.; Kaminska, E.; Adrjanowicz, K.; Dulski, M.; Kossack, W.; Tress, M.; Kipnusu, W.K.; Kaminski, K.; Kremer, F. Molecular dynamics of itraconazole confined in thin supported layers. RSC Adv. 2014, 4, 28432-28438. [CrossRef] 